\title{
Odontoameloblastoma: Report of a Case
}

\section{A. Ferhat Misir ${ }^{1 *}$, Mahmut Sumer ${ }^{2}$ and Bilge Can Meydan ${ }^{3}$}

${ }^{1}$ Assistant Professor, Department of Oral \& Maxillofacial Surgery, Faculty of Dentistry, University of Karaelmas, Zonguldak, Turkey

${ }^{2}$ Associate Professor, Department of Oral \& Maxillofacial Surgery, Faculty of Dentistry, University of Ondokuz Mayis, Samsun, Turkey

${ }^{3}$ Assistant Professor, Department of Pathology, Faculty of Medicine, University of Ondokuz Mayis, Samsun, Turkey

\begin{abstract}
Odontoameloblastoma $(\mathrm{OA})$ is an extremely rare mixed odontogenic tumor with odontogenic mesenchyme displaying the histologic characteristics of ameloblastic fibroma and complex odontoma. OA occurs predominantly in children and young adults. The majority of the tumours are associated with unerupted teeth. OA is generally asymptomatic and occurs in either jaws with slight inclination for mandible. Review of the literature exhibits only four reported cases in the posterior maxilla. This report presents an OA in the posterior region of the maxilla of an 11-yearold female. The lesion was surgically treated, no recurrence has been observed on follow-up.
\end{abstract}

Keywords: Mixed odontogenic tumour; Ameloblastic odontoma; Odontoameloblastoma; Composite odontoma

\section{Introduction}

Odontoameloblastoma $(\mathrm{OA})$ is an extremely rare mixed odontogenic tumour often associated with an impacted tooth, composed of neoplastic epithelium and myxomatous connective tissue [1]. Generally, its clinical presentation resembles an odontoma, thus the definite diagnosis is based on the histologic analysis following an excision and curettage [2]. The Odontoameloblastoma and the complex odontoma belong to a group of odontogenic tumours that consists of odontogenic epithelium and odontogenic ectomesenchyme with or without dental hard tissue formation ('mixed odontogenic tumours') $[3,4]$. However, it's difficult to establish the differential diagnosis of OA with ameloblastic fibro-odontoma or a developing complex odontoma [5].

$\mathrm{OA}$ is usually found in young patients, with no significant gender predilection [6,7]. Clinically, the two main complaints are swelling and failure of tooth eruption. Radiological examination usually reveals a multilocular radiolucency with a well-defined boundary often exhibiting a radiopaque areas resembling mature dental tissue [8]. If an unerupted tooth is present, the tumour is usually situated coronally to the crown of this tooth $[6,8]$. We intend to present a case of OA in the posterior region of the maxilla of an 11-year-old female as well as to compare the clinical and microscopic findings with those of the previously published cases that fulfill the current criteria of OA.

\section{Case Report}

An 11-year-old, healthy female patient was referred to the Department of Oral and Maxillofacial Surgery for the evaluation of an asymptomatic radiographic lesion in the right posterior maxilla. Radiographic examination demonstrated radiopaque lesion resembling mature dental germ with a well-defined margin in the posterior region of the maxilla (Figure 1).

She had no pain or gingival swelling. The overlying mucosa was healthy with no ulceration or tenderness. A provisional diagnosis of complex odontoma, the lesion was excised, under local anesthesia. The lesion which was hard, whitish milky brown colored, measuring $20 \times 10 \times 7 \mathrm{~mm}$. was sent for histopathologic examination (Figure 2).

During enucleation of the lesion the germ of the second molar slightly moved with the lesion however, the surgeon dissected the lesion meticulously and left the germ in the original position. The wound was closed with interrupted sutures.
Light microscopic sections, stained with hematoxylin-eosin and Gomori trichrome, revealed characteristics of ameloblastoma and odontoma. There were irregular mineralized areas indicative of calsifying enamel and dentin adjacent to the ameloblastoma-like epithelial and mesenchymal proliferation areas. The presence of a dental pulp-like mesenchyme and cementum confined to the stratified squamous epithelium. These findings were compatible with OA (Figure 3-5).

The patient has been followed for 4 years with no evidence of recurrence (Figure 6).

\section{Discussion}

Odontoameloblastoma is a rare mixed odontogenic neoplasm, characterized by the simultaneous occurrence of an ameloblastoma and a compound or complex odontoma in the same tumour mass $[3,9]$. Confusion exists when describing OA because the final diagnosis

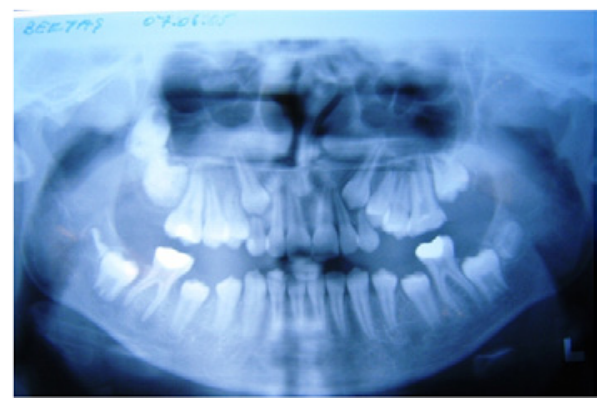

Figure 1: Panoramic radiograph showing a well-defined, germ shaped radiolucent lesion containing a radiopaque mass (black arrow), and causing tooth impaction.

${ }^{*}$ Corresponding author: Ahmet Ferhat Misir, Department of Oral \& Maxillofacial Surgery, Faculty of Dentistry, University of Karaelmas, Zonguldak, Turkey, Tel: +90 372 2613412; Fax: +90 372 2613403; E-mail: afmisir@karaelmas.edu.tr

Received January 26, 2012; Accepted February 21, 2012; Published February 23, 2012

Citation: Misir AF, Sumer M, Meydan BC (2012) Odontoameloblastoma: Report of a Case. Dentistry 2:122. doi:10.4172/2161-1122.1000122

Copyright: ( 2012 Misir AF, et al. This is an open-access article distributed under the terms of the Creative Commons Attribution License, which permits unrestricted use, distribution, and reproduction in any medium, provided the original author and source are credited. 
must be made based on clinical, radiological histopathological features of the lesion, so it has been reported under a variety of names [2]. Several different names exist for this kind of tumour in the literature, including odontoblastoma (Thoma, 1970), adamantodontoma (Schafer et al,1983), calcified mixed odontogenic tumour (Hoffman, 1985), soft and calcified odontoma (Woleyand Mckee, 1972), and ameloblastic odontoma (Hooker, 1967) [8]. However, the term "ameloblastic odontoma" was deleted from "histologic typing of odontogenic tumours, jaw cysts and allied lesions" list by WHO. Later this category was subdivided into ameloblastic fibroodontoma (AFO) and Odontoameloblastoma (OA) [10,11].

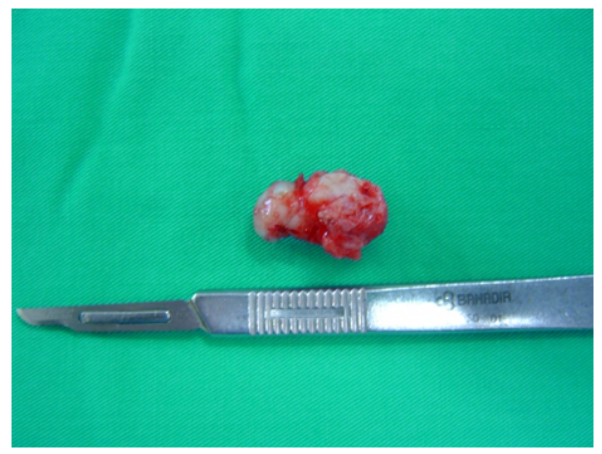

Figure 2: The specimen is hard, whitish milky brown colored, measuring $20 \times 10 \times 7 \mathrm{~mm}$.

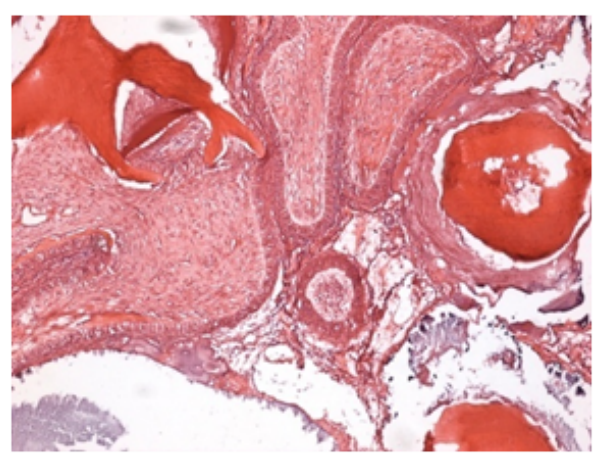

Figure 3: Noncapsulated tumour, showing epithelial and mesenchymal proliferation. Note, there were lots of irregular mineralized areas composed by dentin and empty areas suggestive of demineralized enamel matrix. (Hematoxylin and eosin, original magnification $\times 40$ ).

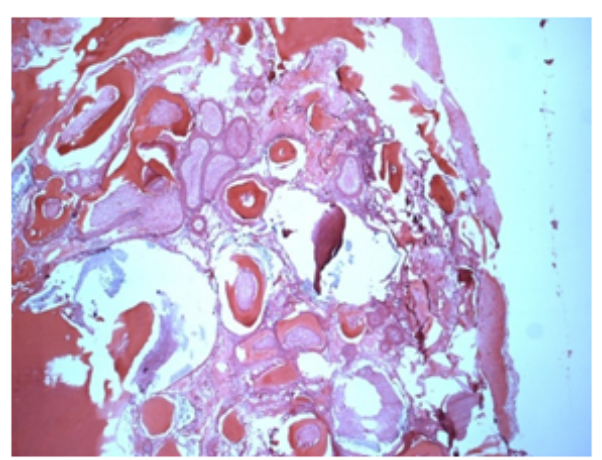

Figure 4: Odontogenic epithelium showing follicular growth pattern surrounded by odontogenic mesenchyme (Hematoxylin and eosin, original magnification $\times 100)$.

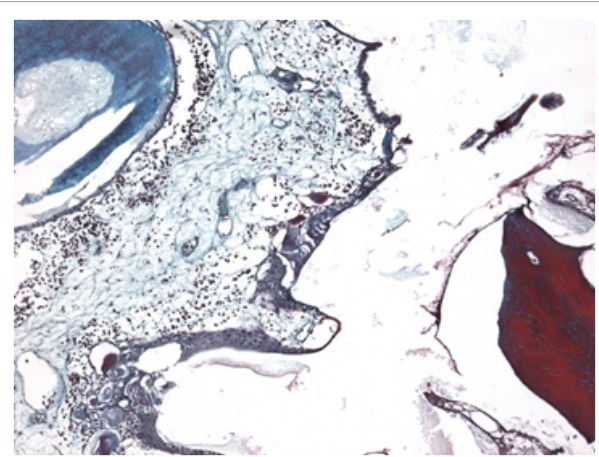

Figure 5: The presence of a dental pulp-like mesenchyme and cementum confined to the stratified squamous epithelium. Ameloblast like cells on the periphery with stellate reticulum like cells (black arrow) (Gomori trichrome, original magnification $\times 100$ ).

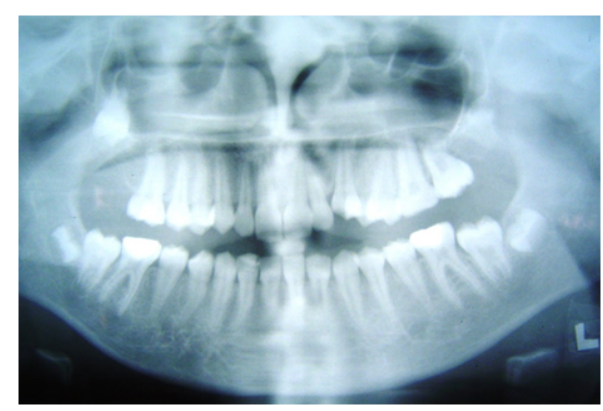

Figure 6: Panoramic radiograph showing no recurrence after 4 years.

The exact incidence of this neoplasm is difficult to determine because the current information on this rare lesion comes from uncombined and single case reports. Review of the literature shows this tumour usually occurs in the posterior segments of either jaw, with a slight predilection for the mandible $[2,8]$. The relative frequency of OA among odontogenic tumours vary between 1 and $3.1 \%$. If patients under the age of 16 are considered separately, $7 \%$ of odontogenic tumours are OA. OA affects predominantly young patients with a median age of 20.12 years (2.7-52). In fact, $59 \%$ of patients are under the age of 15 (Table 1).

According to the cases reported in the English literature; among 26 cases, only 5 cases have been reported involving posterior maxillary region [8]. The aim of this article is to present a rare case of OA in the posterior maxilla.

Clinically OA starts as a slow-growing painless mass that expands the alveolus and vestibular cortex, and prevents the eruption of the permanent teeth [9]. However, in the present case there was no expansion in the alveolus. In most of the presented cases there were symptoms such as swelling or pain, but in this case the tumour was asymptomatic and was detected during a routine examination.

Radiologic examination of OA usually reveals a multilocular radiolucency with radiopaque areas resembling mature dental tissue $[1,2]$. It might exhibit a well-defined margin, displacing the surrounding erupted teeth rather than producing root resorption [9]. Thus, OA is often confused with compound or complex odontomas. Some of the tumours may be relatively small when first detected ( 1 to $2 \mathrm{~cm}$. in diameter). The present case had all of these characteristics. 


\begin{tabular}{|c|c|c|c|c|c|c|}
\hline S.No & Author & Age & Sex & Location & Follow-up & Recurrence \\
\hline 1 & Thoma et al. & 35 & $\mathrm{~F}$ & Molar - mandible & - & - \\
\hline 2 & Thoma \& Goldman & 20 & M & Anterior maxilla & 2 years & Yes \\
\hline 3 & Silva & 2,5 & $\mathrm{~F}$ & Anterior maxilla & 11 months & No \\
\hline 4 & Frissell \& Shafer & 11 & M & Posterior mandible & 4 years & Yes \\
\hline 5 & Choukas \& Toto & 8 & M & Anterior mandible & 18 months & No \\
\hline 6 & Jacobson \& Quinn & $\begin{array}{l}12 \\
20\end{array}$ & $\begin{array}{l}F \\
F\end{array}$ & $\begin{array}{l}\text { Posterior mandible } \\
\text { Posterior maxilla }\end{array}$ & $\begin{array}{l}2 \text { years } \\
10 \text { years }\end{array}$ & $\begin{array}{l}\text { No } \\
\text { No }\end{array}$ \\
\hline 7 & LaBriola et al. & 25 & M & Posterior maxilla & 6 months & No \\
\hline 8 & Gupta \& Gupta & 51 & M & Posterior mandible & 18 months & Yes \\
\hline 9 & Takeda et al. & 11 & $\mathrm{~F}$ & Anterior maxilla & - & - \\
\hline 10 & Thompson et al. & 34 & $\mathrm{~F}$ & Anterior mandible & - & - \\
\hline 11 & Kaugars \& Zussmann & 15 & M & Posterior maxila & 7 months & No \\
\hline 12 & Gunbay \& Gunbay & 11 & M & Anterior maxilla & 7 years & No \\
\hline 13 & Raubenheimer et al. & - & - & - & - & - \\
\hline 14 & Stypulkowska & - & - & - & - & - \\
\hline 15 & Aguado et al. & 52 & $\mathrm{~F}$ & Posterior maxilla & 17 months & No \\
\hline 16 & Goh \& Teh & - & - & - & - & - \\
\hline 17 & Mosqueda et al. & $\begin{array}{l}25 \\
15 \\
9\end{array}$ & $\begin{array}{l}\mathrm{M} \\
\mathrm{M} \\
\mathrm{M}\end{array}$ & $\begin{array}{l}\text { Posterior maxilla } \\
\text { Posterior mandible } \\
\text { Maxilla }\end{array}$ & $\begin{array}{l}6 \text { months } \\
1 \text { year } \\
3 \text { years }\end{array}$ & $\begin{array}{l}\text { No } \\
\text { No } \\
\text { No }\end{array}$ \\
\hline 18 & Palaskar and Nayar & 42 & $\mathrm{~F}$ & Posterior mandible & - & - \\
\hline 19 & Martin-Granizo-Lopez et al. & 12 & $\mathrm{~F}$ & Anterior mandible & 18 months & No \\
\hline 20 & Mosca et al. & $\begin{array}{l}22 \\
16\end{array}$ & $\begin{array}{l}\mathrm{F} \\
\mathrm{M}\end{array}$ & $\begin{array}{l}\text { Anterior maxilla } \\
\text { Posterior mandible }\end{array}$ & $\begin{array}{l}6 \text { years } \\
6 \text { months }\end{array}$ & $\begin{array}{l}\text { No } \\
\text { No }\end{array}$ \\
\hline 21 & Sapru et al. & 36 & M & Posterior mandible & 1 year & No \\
\hline 22 & Dive et al. & 47 & M & Anterior mandible & 2 years & No \\
\hline
\end{tabular}

F: Female, M: Male

Table 1: Literature review of odontoameloblastomas (modified from Ref. 8).

Nevertheless, some OA's may be exceedingly large, involving a considerable portion of the body of the mandible or maxilla [12].

Even though there are a small number of cases, it is suggested that $\mathrm{OA}$ possesses clinical and microscopic features that allow differentiation from typical ameloblastomas and odontomas. OA tends to occur with equal frequency in the mandible and in the maxilla, while ameloblastoma is predominantly seen in the mandible. Odontoma, especially the compound type, tends to occur with higher frequency in the anterior region of the maxilla $[3,12]$.

Additionally, OA tends to produce bone expansion in almost all cases, similar to conventional ameloblastoma, while an odontoma seldom produces swelling of the affected region. Therefore, in many cases OA are often confused with compound or complex odontomas, as in the present case.

A challenging subject with the treatment choice of OA cases, is the decision whether to remove the teeth present in the affected area of the tumour or not. Surgical enucleation is considered to be the treatment of choice in many cases with simultaneous removal of any involved unerupted tooth, since there are case reports of recurrence when conservative treatment, with an attempt to save the associated teeth, is performed [10-13]. Nevertheless, in cases where the production of hard dental tissues is minimal, treatment may be performed without removal of the associated impacted tooth. The eruption sequence of the teeth in the area of the tumour does not appear to be affected $[4,13]$.

Although there was hard dental tissue formation in our case we decided to leave the germ of the permanent right second molar tooth in its original position since no tooth resorption was apparent. Malignant transformation is rare, nevertheless has also been reported [13]. In the 4 years follow-up period there was no sign of recurrence in our case.

In conclusion, $\mathrm{OA}$ is a very rare mixed odontogenic tumour that tends to occur at an earlier age than conventional ameloblastoma. The recurrence of this tumour is associated with the expansion of the alveolus, the resorption of the affected permanent tooth and the radiographical and histological results. Early diagnosis prevents local invasion and neoplastic changes of this tumour which would make the treatment more aggressive.

\section{References}

1. Regezi JA, Sciubba JJ, Jordan RCK (2003) Oral Pathology: Clinical Pathologic Correlations Odontogenic tumours. (4thedn), WB Saunders,USA, 284-286.

2. Martín-Granizo-López R, López-García-Asenjo J, de-Pedro-Marina M Domínguez-Cuadrado L (2004) Odontoameloblastoma: a case report and a review of the literature. Med Oral 9: 340-344.

3. Barnes L, Eveson JW, Reichart P, Sidransky D (2005) World Health Organization Classification of Tumours. Pathology and Genetics of Head and Neck Tumours. Lyon: IARC Press, Chapter 6.

4. Philipsen HP, Reichart PA, Praetorius F (1997) Mixed odontogenic tumours and odontomas. Considerations on interrelationship. Review of the literature and presentation of 134 new cases of odontomas. Oral Oncol 33: 86-99.

5. Reibel J, Grønbaek AB, Poulsen S (2011) Peripheral ameloblastic fibroodontoma or peripheral developing complex odontoma: report of a case. Int $J$ Paediatr Dent 21: 468-470.

6. Mosqueda-Taylor A, Carlos-Bregni R, Ramírez-Amador V, Palma-Guzmán JM, Esquivel-Bonilla D, et al. (2002) Odontoameloblastoma. Clinico-pathologic study of three cases and critical review of the literature. Oral Oncol 38: 800-805.

7. Reichart PA, Philipsen HP, Gelderblom HR, Stratmann U (2004) Ameloblastic fibro-odontoma- report of two cases with ultrastructural study of tumour dental hard structures. Oral Oncol Extra 40: 8-12. 
8. Dive A, Khandekar S, Bodhade A, Dhobley A (2011) Odontoameloblastoma. J Oral Maxillofac Pathol 15: 60-64.

9. Gunbay T, Gunbay S, Oztop F (1993) Odontoameloblastoma: report of a case. J Clin Pediatr Dent 18: 17-20.

10. Soares RC, Godoy PG, Neto JC, De Souza LB, Pinto LP (2006) Ameloblastic fibro-odontoma: Report of a case presenting an unusual clinical course. Int $\mathrm{J}$ Pediatr Otorhinolaryngol Extra 1: 200-203.

11. Okura M, Nakahara H, Matsuya T (1992) Treatment of ameloblastic fibro- odontoma without removal of the associated impacted permanent tooth: report of cases. J Oral Maxillofac Surg 50: 1094-1097.

12. Furst I, Pharoah M, Phillips J (1999) Recurrence of an ameloblastic fibroodontoma in a 9-year-old boy. J Oral Maxillofac Surg 57: 620-623.

13. Howell RM, Burkes EJ Jr (1977) Malignant transformation of ameloblastic fibroodontoma to ameloblastic fibrosarcoma. Oral Surg Oral Med Oral Pathol 43 391-401. 